\title{
Stability Analysis and Failure Mechanisms of Open Pit Rock Slope
}

\author{
Yahdi Azzuhry \\ Azzuhry Consulting Agency, Yogyakarta, INDONESIA \\ yahdi_azzuhry@yahoo.co.id
}

\begin{abstract}
Rock mass in nature tend to be unideal, for it is heterogeneous, anisotropic and has discontinuity. The discontinuities makes anisotropic strength and stress in the rock mass, and also controls the changing of the elastic properties of rock mass. This condition results to disruptions in the rock mass strength balance, and finally drives the slopes to collapse. This study aims to determine the slope failure mechanisms in the area of case study, as well as its variations based on the Rock Mass Rating $(R M R)$, Geological Strength Index (GSI), Slope Mass Rating (SMR), kinematic analysis, numerical analysis and monitoring approach slope movement in a coal mine slope applications. The site investigations were implemented to obtain information about slope collapse. Prior to the collapse, the slope inclination was $38^{\circ}$ with of 94 meters height, strike slope of $\mathrm{N} 245 \mathrm{E}$ and direction of slope surface of $335^{\circ}$. After the collapse, the slope was became $25^{\circ}$; and after the collapse materials were cleared, it was $35^{\circ}$. The discontinuity mapping obtained 5 sets of discontinuities, and the data were developed to obtain the value of $R M R$. The result of piezometer measurements was that at occurrence of collapse, slope elevation was 44.40m. Displacement value from monitoring SSMR showed that when the slope was collapsing in two stages, the first stage value was $70.61 \mathrm{~cm}(\mathrm{a}$ more critical condition, the value was rounded down to $70 \mathrm{~cm}$ to the implementation in modelling) and the second stage value was at $124.25 \mathrm{~cm}$. The value of RMR89 in this study was greater than the value of GSI and SMR. As for the average value, it was obtained 34.67 for $R M R 89$ value and 29.67 for $G S I$ value, these rocks then can be classified into Poor Rock class number IV. The result of kinematic analysis found that sliding planar failure at dips $36^{\circ}$, and wedge failure at dips $36^{\circ}, 35^{\circ}$ and $34^{\circ}$. Acquisition $S M R$ value obtained at 25, 27, 28 and 29. The $S M R$ values classified the rock mass quality into class number IV, the description of the rock mass was relatively poor, the slope stability was low or unstable and the collapse manifold was planar or wedge failure. The result from the analysis of the model with its criteria obtained was that un-collapse conditions at angle $29^{\circ}$. It is recommended to use $29^{\circ}$ angle to repair the slopes, and also recommended for overall high wall slope angle. Type of collapse that occurred on the slope failure mechanisms in all of the analysis that has been done, it is known that the mechanisms involved are complex types (combine of wedge failure, planar failure, and step-path failure) or classified into large scale rock slope failure surface.
\end{abstract}

Keywords: slope stability, kinematic analysis, $R M R, G S I, S M R$

\section{INTRODUCTION}

Geological process that occurs during and after the formation of rock influences rock mass properties, including engineering properties. Natural rock masses tend to be unideal in some regards (Goodman, 1989), such as its heterogeneity, anisotropicity, and discontinuity. The existence of a discontinuity in the rock leads to uneven distribution of strength and stress in all directions of rock mass, elastic properties of the rock mass consequently be changed and eventually lead to disruption of the balance of the rock mass strength and landslides. Discontinuity orientation is a major geological factor affecting the stability of the rock (Wyllie \& Mah, 2004).

This study will provide an overview of the state of discontinuities and other geological factors that affect rock mass quality or rock failure mechanisms. Data collection, kinematic analysis, numerical analysis and monitoring approach slope movement was used to know the slope failure mechanisms in the area of case studies and geological variations. Knowledge of the quality of the rock mass was in the form of material rock mass quality evaluation, which also used in slope mine applications, especially in the case study that occurred in the study area.

\section{STABILITY AND SLOPE FAILURE MECHANISMS}

\subsection{Coal Sedimentary Rocks}

Tucker (2003) divided the sedimentary rocks into four general categories, which are siliciclastic sedimentary rocks, sedimentary biogenic, biochemical and organic (composed of limestone, dolomites, cherts, phosphates, coal and oil shale), chemical sedimentary and volcaniclastic sedimentary rocks (clastic volcano). Graha (1987) divides the sedimentary rocks into five groups, which is based on how the rock formation was formed, as follows: sedimentary detritus (klastika), sedimentary rocks evaporate, coal sedimentary rocks (formed from organic elements, namely from plants), silica sedimentary rocks and carbonate sedimentary rocks. In brief, the factor that influences the position 
of geotechnical is the location of a place that was a sedimentation basin whose existence itself is influenced by plate tectonics force. The tectonic process can be followed by the folding or faulting of rock layering (Sukandarrumidi, 2009).

\subsection{Slope Failure Mechanisms}

Slope failure mechanisms depend on site-specific geological and geotechnical conditions; various types of failure mechanisms can occur in rock slopes. The following is a discussion of the possibility of rock slope failure which has been found and also the most relevant failure type of large-scale slope failure. Karzulovic (2005) in Franz (2009) suggested to classify rock slope failure mechanisms into three main categories, which are failure mechanisms with full control structures, without control structures, and partially or combined structural controls. Traditionally, the most prominent type of failure is the failure circular without dominant structural control, and structurally controlled collapse which is planar, wedge and toppling (Azzuhry, 2015).

Failure mechanism type step-path failure is less known in the literature, either with or without structural control type of failure. However, this type of failure is one most often to occur. From twodimensional point of view, step-path failure is fully controlled by the structure of the rock, where as two sets of discontinuities in the slope and the two sets of strike parallel or nearly parallel to the strike slope encounters, as illustrated in Figure 1a. In the condition of single set of flat dip, the failure will happen if triggered by movement in intact rock bridges, as shown in Figure 1b. Therefore, consideration of the rock bridges are negligible, and the potential for collapse can impact the results of the stability analysis. Hoek et al. (2000) mentioned that a largescale rock slope failure indicates that the two categories alone are not sufficient for the large-scale slope analysis, which is probably more realistic that the various types of failure interacting, for example the failure of a major discontinuity and intact rock failure, as shown in Figure 2.

The important role of intact rock bridges in large-scale slope stability, mentioned by Dight (2006) in Franz (2009), is that the numbers of slope instability have failure of the structure. Brown (2004) in Franz (2009) showed that the failure mechanisms are difficult to predict and step-path failure often happened, which identified after it occurs. Progress of large-scale slope instability in the mine has also been crocheted with seismicity and influenced by the hydrogeological impact. Sullivan (2007) indicated that it would be very easy for the overall stability of the mine to change from acceptable to unacceptable levels, depended on the consideration of the interaction of water and slope deformation in pit slope design.

a) b)

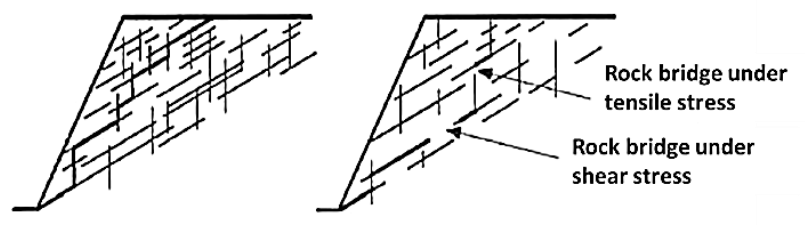

Figure 1. Geometry step-path in rock slopes (Call and Nicholas, 1978 in Franz, 2009): a) Step-continuous path, b) step-path discontinuities with intact rock bridges.

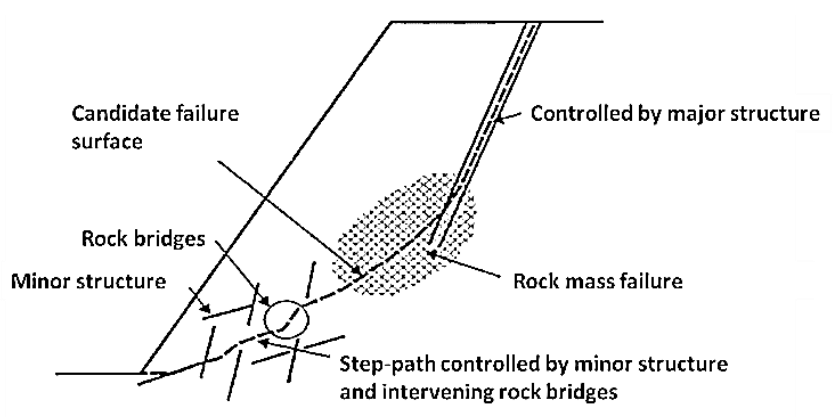

Figure 2. Large scale surface rock slope failure (failure large-scale surface slope) involves a number of different failure mechanisms (Hoek, et al., 2000)

\subsection{Rock Mass Classification}

According to Bieniawski (1989), the geo-mechanics classification Rock Mass Rating (RMR) use six basic parameters for classification and evaluation of test results. These six parameters help to further estimate the stability analysis results, up to the special problems of geomechanics rock. Six parameters that are used to determine the $R M R$ value, includes the Uniaxial Compressive Stress (UCS), Rock Quality Designation (RQD), Spacing of discontinuities, Condition of Discontinuities, Groundwater Conditions and Orientation of Discontinuities (Bieniawski, 1989).

Geological Strength Index (GSI) was introduced in 1994 by Evert Hoek, then developed to help overcome the inability of Bieniawski's rock mass geo-mechanics classification (1974) in determining the poor quality rock mass (Hoek and Marinos (2007)). Hoek, et al. (1998) illustrated the relationship between system formulation or quantitative Geological Strength Index (GSI) and the RMR system of Bieniawski in determining the quality of the rock mass. $R M R$ classification Bieniawski (1989) can be used to estimate the value of GSI, GSI formula $=R M R 89-5$ in full that the value of $R M R 89>23$. Details of the rock mass quality of $R M R 89$ contained in table 1. 
Table 1 . The quality of the rock mass classification $R M R$ (Bieniawski, 1989)

\begin{tabular}{llllll}
\hline Parameter & Rating & & & & \\
\hline Value of $R M R$ & $81-100$ & $61-80$ & $41-60$ & $21-40$ & $<20$ \\
Number Class of $R M R$ & I & II & III & IV & V \\
Value of GSI & $76-95$ & $56-75$ & $36-55$ & $21-35$ & $<20$ \\
Description Rock Mass Quality & Very good rock & Good rock & Fair rock & Poor rock & Very poor rock \\
\hline
\end{tabular}

Tabel 2 Description of class based on SMR (Romana, et al., 2003)

\begin{tabular}{l|lllll} 
Class & I & II & III & IV & V \\
SMR & $81-100$ & $61-80$ & $41-60$ & $21-40$ & $0-20$ \\
$\begin{array}{l}\text { Description of } \\
\text { the rock mass } \\
\text { Stability }\end{array}$ & Very Good & Good & Fair & Bad & Very Bad \\
Type of failure & $\begin{array}{l}\text { Completely } \\
\text { unstable }\end{array}$ & Stable & Partially stable & Unstable & Completely unstable \\
& None & Block failure & $\begin{array}{l}\text { Planar along some joints or } \\
\text { many wedge failure }\end{array}$ & $\begin{array}{l}\text { Planar or big } \\
\text { wedge failure }\end{array}$ & $\begin{array}{l}\text { Big planar or soil- } \\
\text { like or circular }\end{array}$ \\
\hline
\end{tabular}

Slope Mass Rating (SMR) served as geomechanics classification for rock slope. Romana (1993) proposed a modification to the concept of the use of $R M R$ Bieniawski, particularly for slope stability. SMR obtained from $R M R$ by adding the adjustment factor on discontinuity orientation, slope, and other adjustment factors, depending on the method of excavation. Description of the class based on SMR

$S M R=R M R_{\text {basic }}+(F 1 \times F 2 \times F 3)+F 4$

The exposure was evaluated according to the formula wherein $R M R$ basic Bieniawski (1989) with added value for the five parameters: (i) the strength of intact rock, (ii) $R Q D$, (iii) the distance discontinuities, (iv) the condition of discontinuities, and (v) the flow of water through discontinuities or pore pressure ratio. $F 1, F 2$, and $F 3$ were an adjustment factor that is associated with joint orientation, with respect to the slope orientation or slope, and $F 4$ was the correction factor for excavation methods.

\subsection{Slope Stability Analysis}

Slope stability analysis is an action to determine the condition of a slope, aim to estimate the shape and to determine the level of vulnerability to the collapse of the avalanche slope and slope design that meets the security criteria. Slope stability calculations were done based on the finite element method approach with a combination of kinematic analysis and monitoring data with a slope of rock slope stability radar monitoring (SSMR). Two-dimensional model for slope stability analysis was used with the form and the geological condition in the field, it was based on laboratory test data, $R M R$, GSI, kinematic and SMR. Modeling process assisted by the program Plaxis 8 2014 of the Department of Civil and Environmental
Engineering, Gadjah Mada University and Phase2 program to copy the license number $6557 \mathrm{~A}$ (Rocscience Phase2, Hoek, 2012)

\subsubsection{Criteria of Slope Safety Factor}

The safety factor is defined as the factor in which shear strength parameters can be reduced in order to bring the slopes or dam foundation into a state of equilibrium (Morgenstern, 1991, in Hoek, 1991). The safety factor used in conventional geotechnical practice is based on logical experience (Duncan, 2000). Hoek (1991) proposed a design safety factor for various types of rock engineering problems ranging from large safety factor value of 1 for extreme loading, seismic analysis and design of gravity on the dam, a large safety factor value of 1.5 for permanent rock slopes (decomposes in table 3 ) and the value of the safety factor of 2 to block the fall-out in the tunnel.

Table 3 Criteria safety factor Hoek (Hoek, 1991)

\begin{tabular}{ll}
\hline safety factor $(\mathrm{F})$ & Event \\
\hline $\mathrm{F}<1$ & There was a failure \\
$1 \leq \mathrm{F}<1.5$ & Design conditions infeasible field \\
$\mathrm{F} \geq 1.5$ & Feasible design conditions applied field \\
\hline
\end{tabular}

\section{RESEARCH METHOD}

\subsection{Research Location}

The location of this research was the slope of the open pit coal area, which administratively included in Muaralawa Subdistrict and Damai Subdistrict of West Kutai District of East Kalimantan Province (Figure 3). 


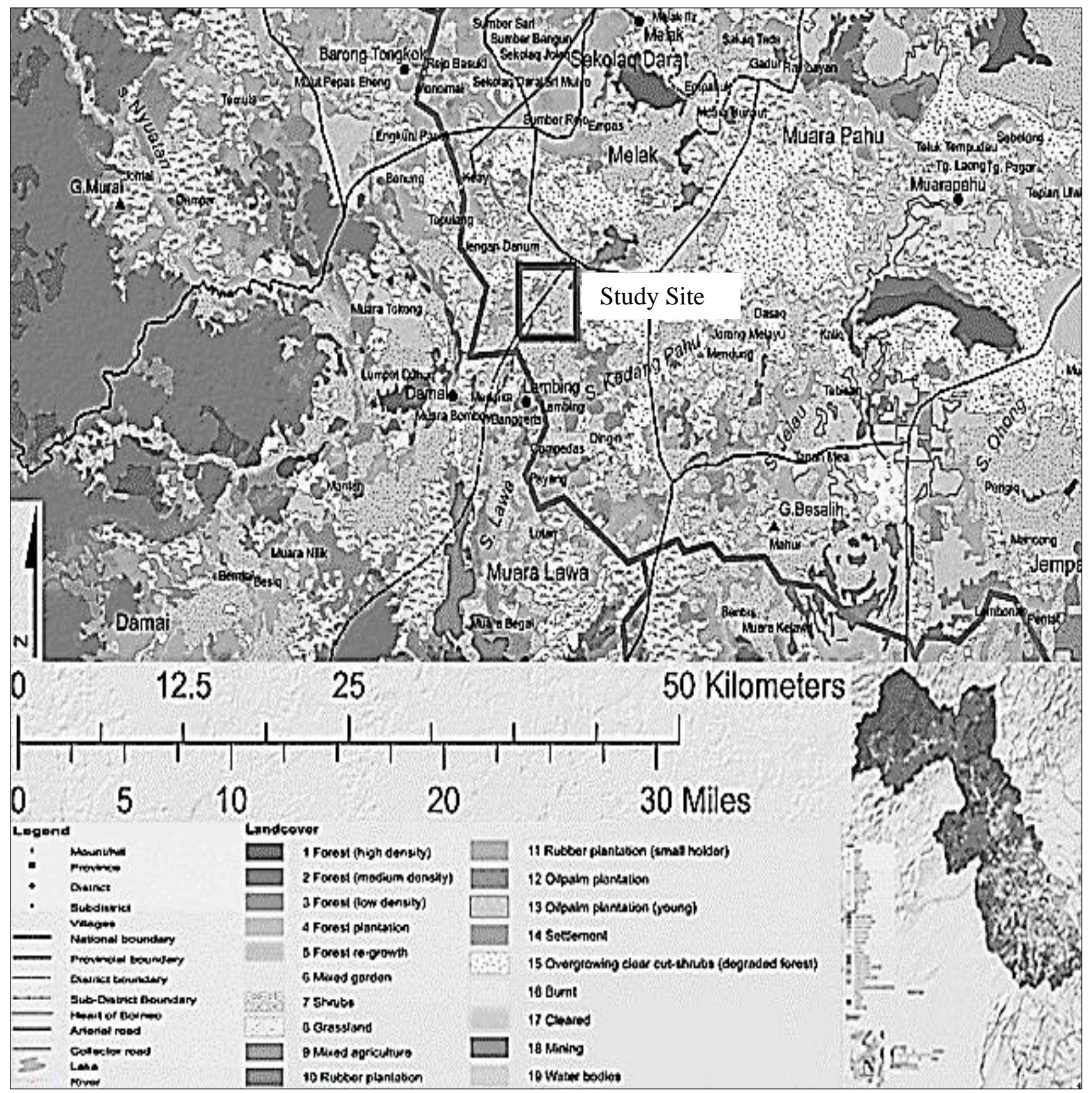

Figure 3. Study site.

\subsection{Research Method}

In this research, several data including rock samples and geological discontinuity orientation were collected. The slope movement was monitored using the Slope Stability Radar or Slope Stability Radar Monitoring (SSMR). Prior to the analysis, the monitored data was selected whether has good quality and in accordance to the field condition. Rock mechanics laboratory test, developed formula, as well as modeling were conducted to obtain the slope stability.

\section{RESULT AND DISCUSSION}

\subsection{Result of Site Investigation}

Geomorphologically, the slope at a time prior to the collapse has $38^{\circ}$ slopes, with a height of $94 \mathrm{~m}$, the slope strike was N $245 \mathrm{E}$ and the slope surface direction was $335^{\circ}$. After the collapse material cleansed, it changed to $35^{\circ}$ slope. The mapping of discontinuities suggested that there was 5 sets of discontinuities of sandstone and siltstone lithology. These data then were analyzed to obtain the value of RMR. From the Piezometer, the ground water level was on $44.40 \mathrm{~m}$ elevation when the slope collapse. Displacement value of SSMR monitoring show that displacements occured in two phases during the 
collapse: the first phase $70.61 \mathrm{~cm}$ (more critical condition value is rounded up to $70 \mathrm{~cm}$ for in implementation of modeling) and the second stage $124.25 \mathrm{~cm}$.

\subsection{Rock Mass Quality Classification and the Relationship Between RMR and GSI}

Based on the site investigation data result, the location of the rock mass classification 1 sandstone lithology $R M R 89$ value was of 36 and GSI value of 31 . Location 1 lithology siltstone $R M R 89$ value of 38 and GSI value of 33. Location 2 sandstone lithology $R M R 89$ value of 30 and GSI value of 25. Statistically, the RMR89 value was greater than the value of GSI, where as for the average value of all locations it was calculated that the RMR89 value of 34.67 and GSI value was of 29.67. From the RMR and GSI result, the rocks, and then can be classified into the rock mass poor quality of Class IV.

\subsection{Results of Kinematic Analysis}

Kinematic analysis was based on data that obtained from site investigation, which is a set major data from each set that were obtained from discontinuities mapping. Due to a view that data obtained from discontinuity mapping of slope pre-collapse was a similar station, then analysis will be conducted with the option of all the data combined into one. Set major which was used as input in the kinematic analysis consisted of two set major of stereographic projection of combined results of all data from each station (for first phase analysis) and 5 set major from mapping discontinuity result (for second phase analysis). Each phase will be analyzed according to the rules Kinematic Analysis of Goodman (1989), as for the data limit of slope of the cut strike N245E was used, with slope angle of $38^{\circ}$, and the average internal shear angle of $23^{\circ}$.

Stereographic projection of the combined data mapping produces two set major of joint, first joint set (J1) which resulted a set major strike of joint N $226 \mathrm{E}$ and set major dip of joint $36^{\circ}$; second joint set (J2) resulted in a set major strike of joint $\mathrm{N} 303 \mathrm{E}$ and set major dip of joint $48^{\circ}$, as shown in Figure 3. The results of the kinematic analysis first phase were two types of collapse, namely sliding planar and wedge failure failure, the stereographic projection exposure can be seen in Figure 5. The stereographic projection for the kinematic analysis of the second phase was using the 5 sets of joint major discontinuity of the mapping. The results of the second phase kinematic analysis found manifold collapse wedge failure, collapse was found in 6 line intersection IIJ created, detailed kinematic analysis stereographic projection can be seen in Figure 6.

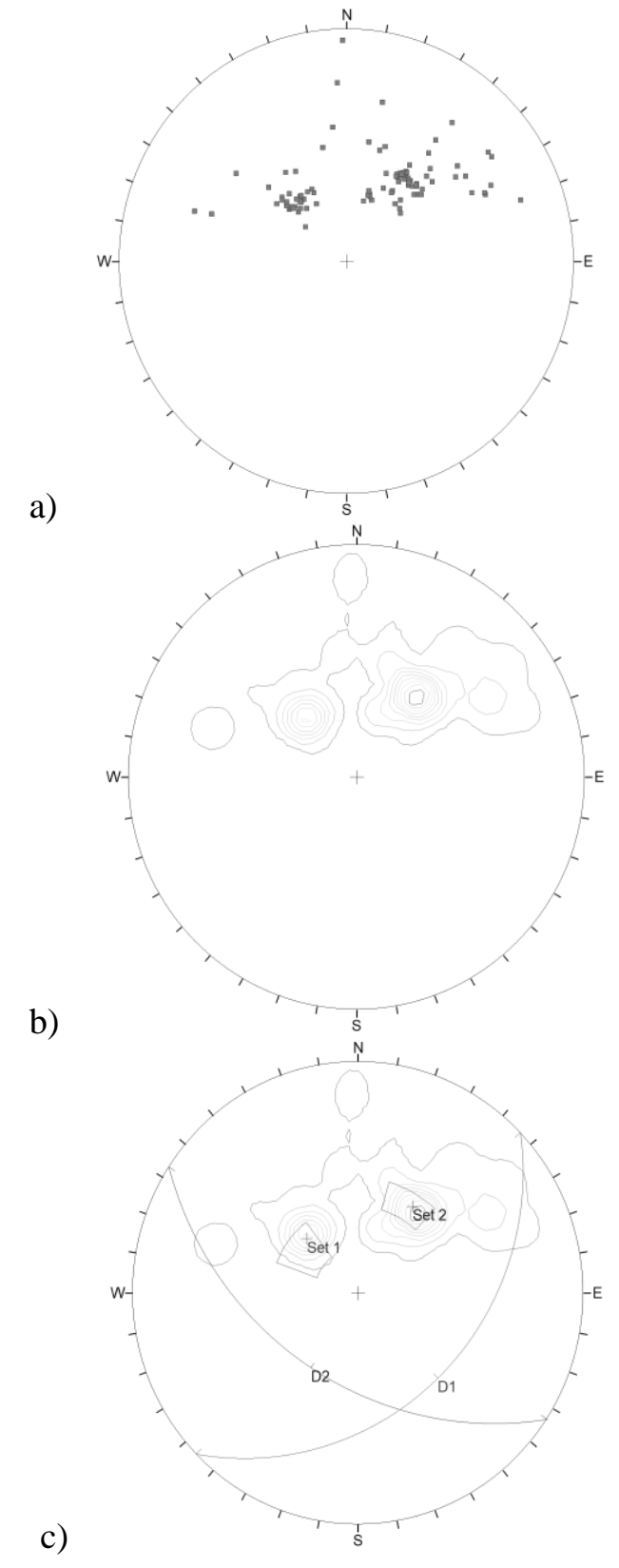

Figure 4. Plot point of discontinuity of all the data station. a) plot normal vector, b) plot contour, c) jointly set major

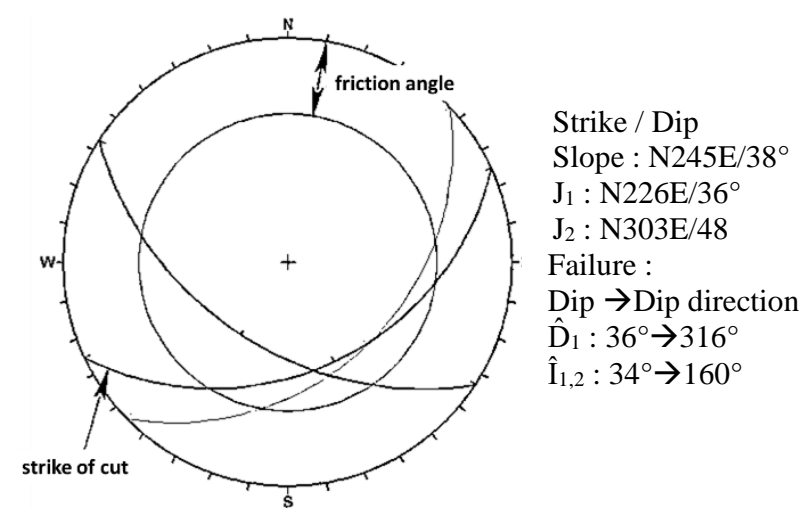

Figure 5. stereographic projection in the kinematic analysis of the first stage. ( $\mathrm{J}$ : joint set, $\phi$ : friction angle, $\hat{\mathrm{D}}: \operatorname{dip}$ vector, Iij : line intersection) 


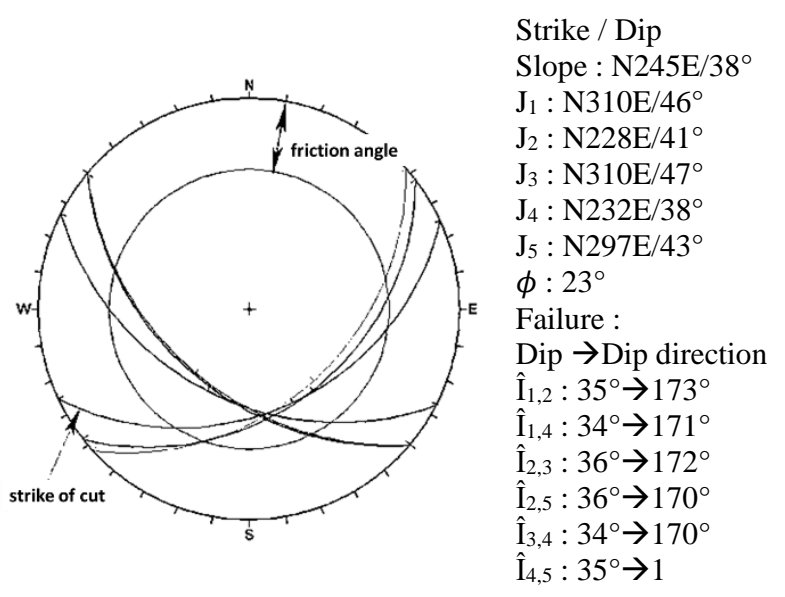

Figure 6. stereographic projection in the second stage kinematic analysis ( $\mathrm{J}$ : joint set, $\phi$ : friction angle, $\hat{\mathrm{Iij}}$ : line intersection)

\subsection{Results Analysis of Slope Mass Rating}

Data input in this analysis used an average value of $R M R 89$ of 34.67 , and the discontinuity orientation data was taken from the results of the kinematic analysis that was belonged to the category of collapse. In this calculation, the value of F3 was taken from Bieniawski rating for joint orientation adjustment in RMR89 parameters, where as the value was a reflection of the relationship between slope and joints dips, with value of -25 . The field excavation method was using normal blasting techniques and was helped with mechanical device. The excavation activity did not alter the stability of the slope, so the adjustment factor F4 value was 0 .

SMR analysis results, shown in Table 5, explained statistically that $R M R$ value was greater than the value of $S M R$ and generated range of $S M R$ values, the smallest was of 25, and largest value of 29. By SMR analysis (Romana et al., 2003), the value range included into the rock mass quality class IV, description of the rock mass was relatively poor, the stability of the slope was unstable, and collapse type was planar or wedge failure. Hoek and Bray (1981) mentioned the economic consequences of the slope instability as a factor of consideration. Selection of slope angles used will use the results of finite element analysis of the most efficient because the smallest value of $S M R$ in this study was less economical to be applied as mine slope.

\subsection{Results of Finite Element Modelling}

Process modelling in this study using several limitations, which were the numerical model used was in form of two-dimensional, analysed in plane strain, the magnitude of the angle used was taken from the initial slope angle before the collapse, the results of the kinematic analysis and SMR analysis (overall angle used in the model is $38^{\circ}, 36^{\circ}, 35^{\circ}, 34^{\circ}, 29^{\circ}, 28^{\circ}$, $27^{\circ}$ and $25^{\circ}$ ), the depth of water table used was the depth of water at a time when the slopes of collapse in elevation $44.40 \mathrm{~m}$, and in making decisions regarding to condition of collapse, the models are validated by the data monitoring results SSMR displacement at time when the slope collapse in the first stage with value of $70 \mathrm{~cm}$. One of the slope modeling results at $38^{\circ}$ angle was the total displacement value of slope surface of $0.700 \mathrm{~m}$ in the slope top section, with the value of this, the model was declared in state of collapse, these conditions can be seen in Figure 7.

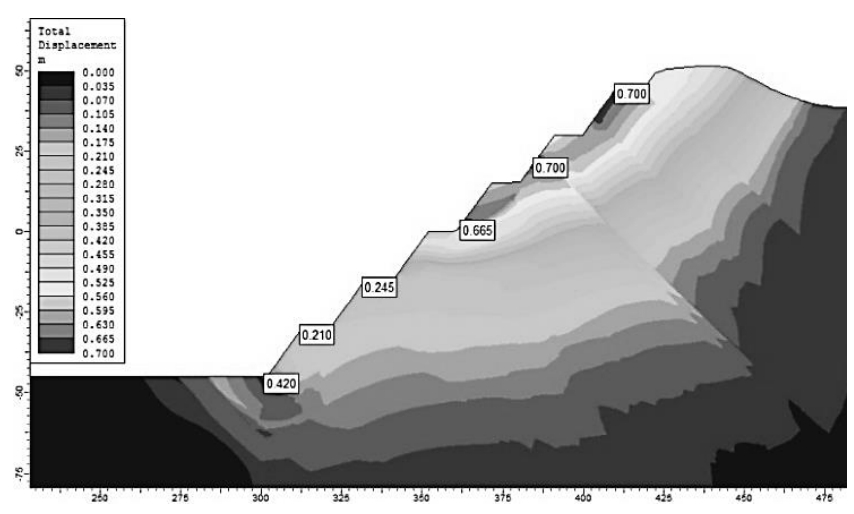

Figure 7. Result of total displacement from slope modeling with overall angle of $38^{\circ}$.

Table 5. Results of continuous slope mass rating (Continuous SMR)

\begin{tabular}{|c|c|c|c|c|c|c|c|c|c|c|c|}
\hline \multirow{2}{*}{$\begin{array}{l}\text { Stages } \\
\text { Kinematic } \\
\text { Analysis }\end{array}$} & \multirow{2}{*}{$\begin{array}{l}\text { type } \\
\text { Vectors }\end{array}$} & \multicolumn{2}{|c|}{ Slope Orientation } & \multicolumn{2}{|c|}{ Joint Orientation (Kinematic) } & \multirow{2}{*}{ RMR } & \multirow{2}{*}{$\mathrm{F} 1$} & \multirow{2}{*}{$\mathrm{F} 2$} & \multirow{2}{*}{ F3 } & \multirow{2}{*}{ F4 } & \multirow{2}{*}{ SMR } \\
\hline & & Dip & Dip Direction & Dip & Dip Direction & & & & & & \\
\hline \multirow[t]{2}{*}{$\mathrm{I}$} & D1 & $38^{\circ}$ & $335^{\circ}$ & $36^{\circ}$ & $316^{\circ}$ & 34.67 & 0.45 & 0.53 & -25 & 0 & 29 \\
\hline & $\mathrm{I} 1,2$ & $38^{\circ}$ & $335^{\circ}$ & $34^{\circ}$ & $160^{\circ}$ & 34.67 & 0.83 & 0.45 & -25 & 0 & 25 \\
\hline \multirow[t]{6}{*}{ II } & $\mathrm{I} 1,2$ & $38^{\circ}$ & $335^{\circ}$ & $35^{\circ}$ & $173^{\circ}$ & 34.67 & 0.48 & 0.49 & -25 & 0 & 29 \\
\hline & $\mathrm{I} 1,4$ & $38^{\circ}$ & $335^{\circ}$ & $34^{\circ}$ & $171^{\circ}$ & 34.67 & 0.52 & 0.45 & -25 & 0 & 29 \\
\hline & $\mathrm{I} 2,3$ & $38^{\circ}$ & $335^{\circ}$ & $36^{\circ}$ & $172^{\circ}$ & 34.67 & 0.50 & 0.53 & -25 & 0 & 28 \\
\hline & $\mathrm{I} 2,5$ & $38^{\circ}$ & $335^{\circ}$ & $36^{\circ}$ & $170^{\circ}$ & 34.67 & 0.55 & 0.53 & -25 & 0 & 27 \\
\hline & $\mathrm{I} 3,4$ & $38^{\circ}$ & $335^{\circ}$ & $34^{\circ}$ & $170^{\circ}$ & 34.67 & 0.55 & 0.45 & -25 & 0 & 28 \\
\hline & $\mathrm{I} 4,5$ & $38^{\circ}$ & $335^{\circ}$ & $35^{\circ}$ & $168^{\circ}$ & 34.67 & 0.60 & 0.49 & -25 & 0 & 27 \\
\hline
\end{tabular}


Table 6. Safety Factor of results the analysis of the model along with the criteria

\begin{tabular}{llll}
\hline $\begin{array}{l}\text { Slope angle } \\
\text { on the model }\end{array}$ & $\begin{array}{l}\text { Safety Factor } \\
\text { model results }\end{array}$ & \multicolumn{2}{l}{ Description of the acquisition of Safety Factor } \\
\cline { 3 - 4 } 38 & 1.45 & Criteria of Evert Hoek (1991) & Criteria of limitation in the analysis of the model \\
36 & 1.53 & Infeasible implemented & failure \\
35 & 1.57 & Feasible implemented & failure \\
34 & 1.58 & Feasible implemented & failure \\
29 & 1.58 & Feasible implemented & failure \\
28 & 1.59 & Feasible implemented & not failure \\
27 & 1.62 & Feasible implemented & not failure \\
25 & 1.67 & Feasible implemented & not failure \\
\hline
\end{tabular}

The positions of the three highest value of total displacement on the model were given further analysis by issuing a chart comparison of the displacement with the safety factor value. From the first analysis of the first position point total displacement of over $0.700 \mathrm{~m}$ worth (point A), it was obtained that the value of safety factor was 1.57. Analysis of total displacement point second position of the top was $0.700 \mathrm{~m}$ (point B) obtained value of safety factor 1.38 and the third point of the statistical analysis on value of $0.665 \mathrm{~m}$ (point $\mathrm{C}$ ) obtained value of safety factor 1.41, details can be seen in Figure 8. The three safety factor values were on average value of 1.45.

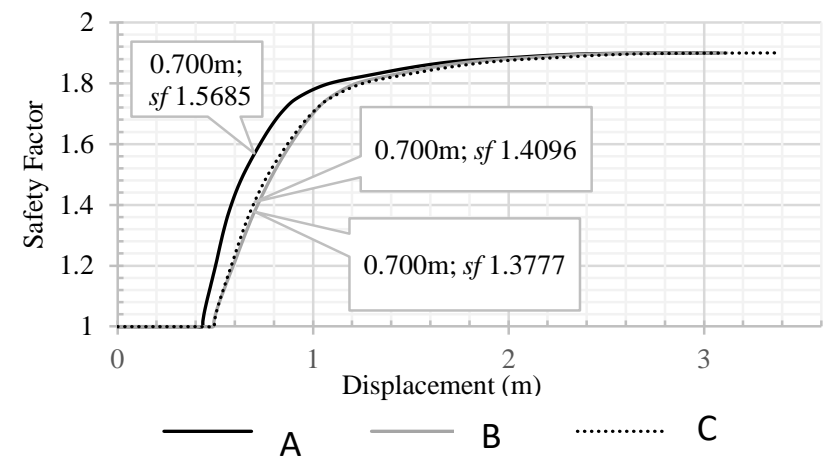

Figure 8. Safety factor graphic to displacement of model result on $38^{\circ}$ angle

Based on the results of the kinematic analysis and $S M R$ can be accepted due to the influence of the structure occurs. The economic view of the slopemaking process was considering the large volume of excavated material, in which the more sloping the angle, the more the volume of material to be demolished, and the use of funds will be higher as well. To strengthen the decision making, the initial slope angles and all part of the analysis results were reviewed with the help of finite element program, and also to increase confidence in the decision-making, the results obtained were examined from all aspects of safety factor criteria, as listed in Table 6.

The results of the model of the acquisition of Safety Factor showed the initial slope was experiencing a critical condition, or not feasible in the field when viewed from the side of the criteria Hoek (1991). The result of safety factor in Table 6 showed that there should be justification engineering, particularly regarding models slope angle of $38^{\circ}$, with the results of the model Safety Factor of value 1.45, that the actual state of the field has experienced a break. This was because the implementation of the model analysis calculations was using input data properties intact rock. The model followed by a reverse analysis of the parameters Cohesion, Friction Angle and Young's Modulus, thus gaining Safety Factor value close to the value 1 and value approaches the Extreme Total Displacement Displacement field monitoring results for $124.25 \mathrm{~cm}$. The results of the reverse analysis on the model of the slope angle of $38^{\circ}$ was that Safety Factor value of 1.04, and Extreme Total Displacement value of $124 \mathrm{~cm}$.

The decision making for the implementation of the plan of slope angle on the overall high wall in the mine area for further progress was advised to use angle $29^{\circ}$. This decision was drawn from the results of the model analysis in which its criteria obtained the condition of not collapsing at an angle of $29^{\circ}$.

\subsection{Slope Failure Mechanism Analysis}

The previously conducted analysis stages of analysis can be used as a guide to determine the slope failure mechanisms. Determination stage of slope failure mechanisms was also influenced by specific geological and geotechnical conditions. Geologically specific could be seen from the rock structure (discontinuity in rocks), and geotechnically represented by the performed analysis stage. Kinematic analysis and $S M R$ can be categorized in the analysis of failure mechanisms in the control structure. Analysis of the finite element models was included in the combination of several collapse mechanism.

Collapse with type of planar or big wedge failure was found from the SMR analysis results. The use of the cut of the strike of the slopes at an angle of $38^{\circ}$, through kinematic analysis, found a combination of 
several types of collapse, namely a combination of planar sliding failure, and wedge failure. These conditions can be viewed in three dimensions (3D) in Figure 9, which was obtained from the topographic mapping the location of collapse. The visible image exposure condition of structure influence, in which forming a combination of two wedge failure, then formed a planar failure.

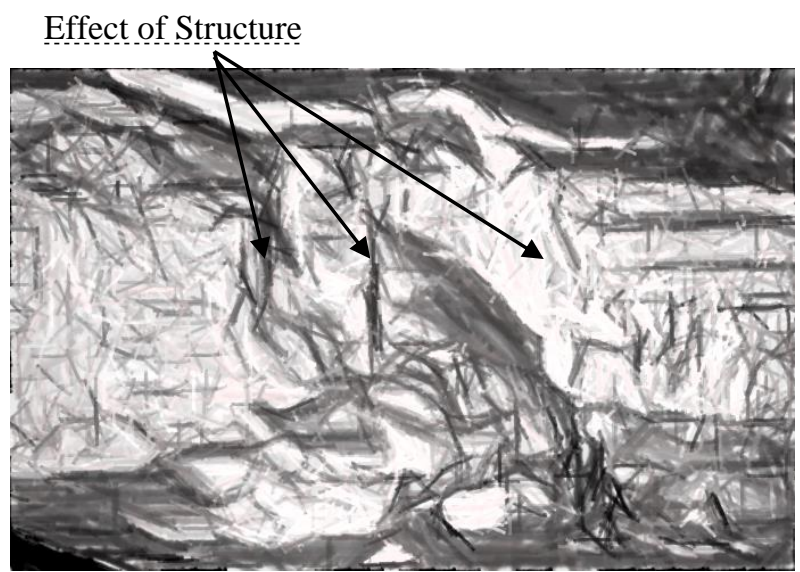

Figure 9. Three-dimensional mapping of the collapse.

Failure mechanisms found from the pattern contour of the total displacement value with $70 \mathrm{~cm}$ restrictions in finite element analysis formed a line of collapse pattern controlled with rock structures (step-path failure), as shown in Figure 10. From the conclusions about the type of collapse that occurred on the slope failure mechanisms in all the analysis that have been done, it can be seen that the mechanisms involved are complex types (combined wedge failure, planar failure, and step-path failure), or classified into large scale rock slope failure surface.
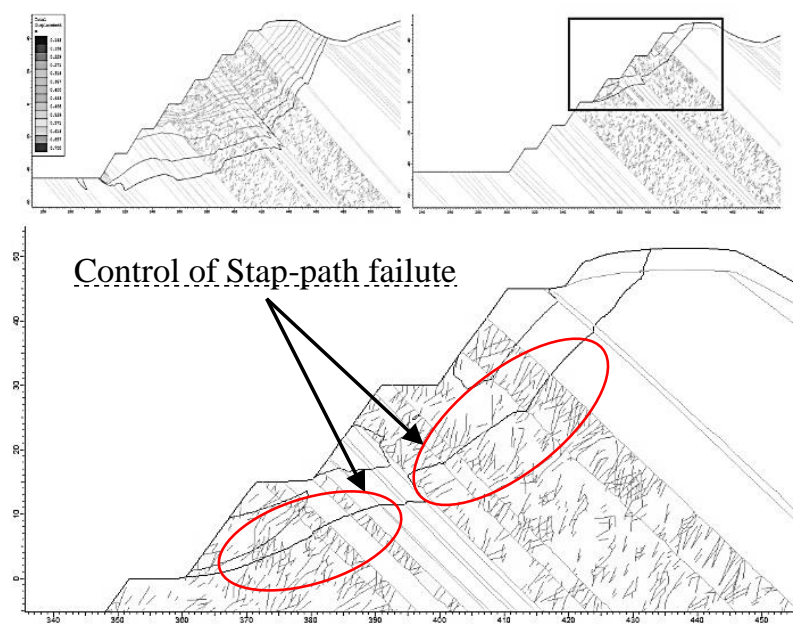

Figure 10. The mechanism of the collapse of the total pattern of discontinuities

\section{CONCLUSIONS}

Based on the results of research and analysis of the data in this study, there are some conclusions as follows:

a) Classification of rock masses for location 1 sandstone lithology RMR89 values obtained at 36 and GSI value of 31. Location 1 lithology siltstone $R M R 89$ values obtained at 38 and GSI value of 33 . Location 2 sandstone lithology RMR89 values obtained at 30 and the value of GSI by 25 . In statistics obtained $R M R 89$ value was greater than the value of GSI which was the average of all locations, obtained the RMR89 value of 34.67 and GSI value of 29.67. Of the acquisition value of $R M R$ and GSI were obtained, these rocks can be classified into the Rock Mass Quality Poor by Number Class IV.

b) The kinematic analysis was done in two stages. The first stage has two types of collapse, which is the discovery of a planar sliding failure at an angle of $36^{\circ}$, and a wedge at an angle of $34^{\circ}$. The second stage has a wedge-type collapse failure of the 6 line intersection with the smallest angle of $34^{\circ}$ and the largest angle of $36^{\circ}$.

c) Statistically that $R M R$ value was greater than the value obtained $S M R$ and $S M R$ values of $25,27,28$ and 29. The range of greatest worth that value into the rock mass quality grade IV, the description of the rock mass was classified as poor, unstable slope stability condition and planar manifold collapse or big wedge failure.

d) Safety factor of results the initial slope of the model was looking to experience a critical condition or not feasible in the field when viewed from the side of the criteria Hoek (1991). The results obtained from the analysis of the model, obtained condition did not collapse at an angle of $29^{\circ}$. Through all of the criteria in the analysis of the decision was taken to recommend the angle of $29^{\circ}$ as the collapsed slope repair and design of the overall slope angle on the high wall mining sites.

e) The type of collapse that occurred on the slope failure mechanisms in all analysis that have been done, it can be seen that the mechanisms involved are complex types (combined wedge failure, planar failure, and step-path failure) or classified into large scale rock slope failure surface.

f) Efforts to get more comprehensive results in stability analysis and failure mechanisms of sedimentary rock slopes could use a combination of Kinematic Analysis and Numerical Analysis. 


\section{REFERENCES}

Azzuhry, Y., 2015. Analisis Stabilitas Dan Mekanisme Keruntuhan Lereng Batuan Sedimen Tambang Terbuka Batubara [Stability Analysis and Mechanism of Slope Failure of Bed Rock in Open Pit Coal Mining], Yogyakarta: Master Thesis, Department of Civil and Environmental Engineering, Universitas Gadjah Mada.

Bieniawski, Z. T., 1989. Engineering Rock Mass Classifications. A Complete Manual for Engineers and Geologists in Mining, Civil and Petroleum Engineering. Toronto: john Wiley \& Sons.

Duncan, J., 2000. Factors of safety and reliability in geotechnical engineering. J. Geotechnical and Geoenvironmental Engineering, April.pp. 307-316.

Franz, J., 2009. An investigation of Combined Failure Mechanisms In Large Scale Open Pit Slopes, Sydney: University of New South Wales, Australia.

Goodman, R. E., 1989. Introduction to Rock Mechanic. 2nd ed. Toronto: John Wiley \& Sons.

Graha, D. S., 1987. Batuan dan Mineral. Bandung: Nova.

Hammah, R. et al., 2007. Analysis of blocky rock slopes with finite element shear strength reduction analysis. In Proceedings of the 1st Canada-U.S. Rock Mechanics Symposium, Vancouver, Canada, pp. 329334.

Hammah, R., Yacoub, T. \& Curran, J., 2009. Numerical Modelling of Slope Uncertainty Due to Rock Mass Jointing. International Conference on Rock Joints and Jointed Rock Masses, 4-10 January.

Hoek, E., 1991. When is a design in rock engineering acceptable?. Proceedings of the 7th International Congress on Rock Mechanics, Aachen, Volume 3, pp. 1485-1497.

Hoek, E. \& Bray, J., 1981. Rock Slope Engineering. 3th ed. London: The Institution of Mining and Metallurgy.

Hoek, E. \& Marinos, P., 2007. A Brief History Of The Development Of The Hoek-Brown Failure Criterion. Soils and Rocks, November.
Hoek, E., Marinos, P. \& Benissi, M., 1998. Applicability of the Geological Strength Index (GSI) CLassification for Very Weak and Sheared Rock Masses. The case of The Athens Schist Formation. Bull. Eng. Geol. Env., Volume 2, pp. 151-160.

Hoek, E., Read, J., Karzulovic, A. \& Chen, Z. Y., 2000. Rock slopes in Civil and Mining Engineering. International Conference on Geotechnical and Geological Engineering, GeoEng2000, 19-24 November.pp. 1-17.

Plaxis, 2007. Plaxix 2D - Versi 8. Netherlands: Plaxis bv..

Rocscience, 2011. Phase2, 2D Elasto Plastic Finite Element Program for Slope and Excavation Stability Analyses, Slope Stability Verification Manual. Toronto,: Rocscience Inc..

Romana, M., Serón, J. B. \& Montalar, E., 2003. SMR Geomechanics Classification: Application, Axperience and Validation. ISRM 2003-Technology roadmap for rock mechanics, South African Institute of Mining and Metallurgy, 12 September.Volume 2.

Romana, M., Serón, J. B. \& Montalar, E., 2003. SMR Geomechanics classification: Application, experience and validation. ISRM 2003-Technology roadmap for rock mechanics, South African Institute of Mining and Metallurgy.

Sukandarrumidi, 2009. Barubara dan Pemanfaatannya, Pengantar Teknologi Batubara Menuju Lingkungan Bersih. Yogyakarta: Gadjah Mada University Press.

Sullivan, T., 2007. Hydromechanical coupling and pit slope movements.. InY. Potvin (ed.), Slope Stability 2007 - Proceedings of the 2007 International Symposium on Rock Slope Stability in Open Pit Mining and Civil Engineering, Perth, 12-14 September.pp. 3-43.

Tucker, M. E., 2003. Sedimentary Rocks in the Field, The Geological Field Guide Series. 3th ed. West Sussex: John Wiley \& Sons.

Wyllie , D. C. \& Mah, C. W., 2004. Rock Slope Engineering, Civil and mining. 4th ed. New York: Spon Press. 
